\title{
Treatment with neutralising antibody against cytokine induced neutrophil chemoattractant (CINC) protects rats against acute pancreatitis associated lung injury
}

\author{
M Bhatia, M Brady, J Zagorski, S E Christmas, F Campbell, J P Neoptolemos, J Slavin
}

Department of Surgery, University of Liverpool, Royal Liverpool University Hospital, Liverpool, UK

M Bhatia

M Brady

J P Neoptolemos

J Slavin

Department of

Immunology,

University of

Liverpool, Royal

Liverpool University

Hospital, Liverpool,

UK

S E Christmas

Department of Pathology, University of Liverpool, Royal

Liverpool University Hospital, Liverpool, UK

F Campbell

David Axelrod Institute, Wadsworth Center, Albany, New York, USA

J Zagorski

Correspondence to: Dr M Bhatia, Department of Surgery, University of Liverpool, 5th Floor UCD Building, Royal Liverpool University Hospital, Daulby Street, Liverpool L69 3GA, UK.

mbhatia@liverpool.ac.uk

Accepted for publication 22 June 2000

\begin{abstract}
Background-Lung injury manifest clinically as adult respiratory distress syndrome (ARDS) is a common cause of morbidity and mortality following acute pancreatitis (AP). Neutrophils play a critical role in the progression of $\mathrm{AP}$ to ARDS. C-x-C chemokines are potent neutrophil chemoattractants and activators and have been implicated in AP.

Aims-To evaluate the effect of blocking the $\mathrm{C}-\mathrm{x}-\mathrm{C}$ chemokine, cytokine induced neutrophil chemoattractant (CINC), in $A P$ on pancreatic inflammation and the associated lung injury in rats.

Methods-AP was induced by hourly intraperitoneal injections of caerulein. Goat anti-CINC antibody was administered either before or after starting caerulein injections to evaluate the prophylactic and therapeutic effects, respectively. Severity of AP was determined by measuring plasma amylase, pancreatic water content, and pancreatic myeloperoxidase (MPO) activity as a measure of neutrophil sequestration in the pancreas. Lung injury was determined by measurement of pulmonary microvascular permeability and lung MPO activity.
\end{abstract}

Results-Treatment with anti-CINC antibody had little effect on caerulein induced pancreatic damage. However, it reduced the caerulein mediated increase in lung MPO activity as well as lung microvascular permeability when administered either prophylactically (lung MPO (fold increase over control): $1.53(0.21) v 3.30$ $(0.46), \mathrm{p}<0.05$; microvascular permeabil$\begin{array}{llllll}\text { ity }(\mathrm{L} / \mathrm{P} \%): & 0.42 & (0.07) & v & 0.77 & (0.11) \text {, }\end{array}$ p $<0.05$ ) or therapeutically (lung MPO (fold increase over control): $2.13(0.10) v$ $4.42(0.65), p<0.05$; microvascular permeability (L/P\%): $0.31(0.05) \quad v 0.79$ (0.13), $\mathrm{p}<0.05$ ).

Conclusion-Treatment with anti-CINC antibody afforded significant protection against pancreatitis associated lung injury. These results suggest that CINC plays an important role in the systemic inflammatory response in AP.

(Gut 2000;47:838-844)

Keywords: chemokines; acute pancreatitis; caerulein; adult respiratory distress syndrome
Acute pancreatitis (AP) is a common disease; the incidence in the $\mathrm{UK}$ is about 40 cases per 100000 population and has been increasing over recent years with an overall mortality of approximately $7.5 \% .^{12} \mathrm{AP}$ has many different causes; activation of digestive enzymes within pancreatic acinar cells is thought to be a critical initiating event. Pancreatic damage then leads to a localised inflammatory response. Leucocyte derived products contribute to local damage and to the subsequent systemic inflammatory response syndrome (SIRS), which if marked leads to multiple organ dysfunction syndrome (MODS) and is the major cause of death $^{3}$

The chemokines are a family of small (8-10 $\mathrm{kDa}$ ) inducible secreted cytokines with chemotactic and activating effects on leucocyte subsets. They can be divided into two major subgroups on the basis of the orientation of the first two cysteines. C-C chemokines principally affect monocytes while $\mathrm{C}-\mathrm{x}-\mathrm{C}$ chemokines which contain the tripeptide sequence ELR at the $\mathrm{NH}_{3}$ terminal tend to act on neutrophils. ${ }^{34}$ Very little work has as yet been undertaken to evaluate the role of chemokines in AP. Interleukin 8 (IL-8) is the best characterised of the ELR positive $\mathrm{C}-\mathrm{x}-\mathrm{C}$ chemokines. Plasma levels of IL-8 are elevated early in the course of an attack in patients with AP and correlate with disease severity. ${ }^{5}$ An antihuman IL-8 antibody was recently shown to reduce lung injury in a rabbit model of AP induced by retrograde injection of 5\% chenodeoxycholic acid. ${ }^{7}$ However, this model is not a well established model of AP and the criteria for lung injury were entirely histological, which can be very subjective. There is little published work examining the role of $\mathrm{C}-\mathrm{C}$ chemokines in $\mathrm{AP}$ although knockout mice deficient in the $\mathrm{C}-\mathrm{C}$ receptor CCR-1 have recently been shown to be protected against AP associated lung injury. ${ }^{8}$

We have recently shown that circulating levels of the human ELR positive C-x-C chemokine GRO- $\alpha$ are elevated in AP and that levels correlate with disease severity (Shokuhi S, Bhatia M, Slavin J, et al, unpublished). There is no direct homologue of IL- 8 in the rat. The

Abbreviations used in this paper: $\mathrm{AP}$, acute pancreatitis; ARDS, adult respiratory distress syndrome; MPO, myeloperoxidase; MODS, multiple organ dysfunction syndrome; SIRS, systemic inflammatory response syndrome IL-8, interleukin-8; CINC, cytokine induced neutrophil chemoattractant; FITC, fluorescein isothiocyanate. 
best characterised of the rat $\mathrm{C}-\mathrm{x}-\mathrm{C}$ chemokines is cytokine induced neutrophil chemoattractant (CINC), the homologue of the human GRO- $\alpha .^{9-11}$ We have recently shown an increase in systemic CINC levels in rats following induction of $\mathrm{AP}^{12} \mathrm{~A}$ neutralising antibody against CINC has been used to establish its importance as a mediator in a range of inflammatory conditions, including peritonitis, shock associated lung injury, and cerebral ischaemia. ${ }^{13-16}$ This antibody is specific for CINC and does not cross react in vivo with the related chemokines CINC2 and CINC3 (MIP2). ${ }^{13}$ Caerulein induced pancreatitis in the rat is a widely used model for AP. The aim of this study was to examine the effect of an anti-CINC neutralising antibody on pancreatic inflammation and the associated lung injury in $\mathrm{AP}$ induced by caerulein in rats.
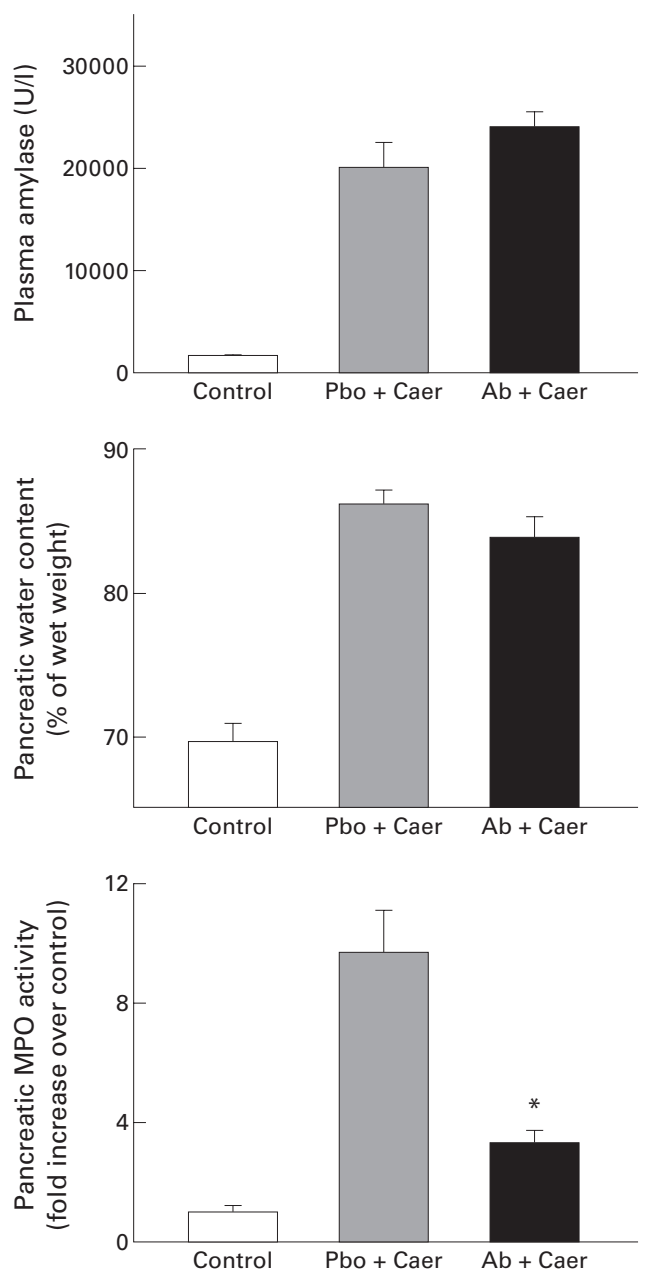

Figure 1 Effects of prophylactic treatment with anti-cytokine induced neutrophil chemoattractant antibody (anti-CINC antibody) on acute pancreatitis. The results shown are mean (SEM) for eight animals in each group. The results are as follows: plasma amylase (U/l) - control 1593 (54); placebo (Pbo) followed by caerulein (Caer) 20 206 (2374); anti-CINC antibody (Ab) followed by Caer 24266 (1391); pancreatic water content (\% of wet weight) - control 69.7 (1.2); Pbo followed by Caer 86.4 (1.0); Ab followed by Caer 84.1 (1.4); pancreatic myeloperoxidase (MPO) activity (fold increase over control) - control $1.0(0.26) ;$ Pbo followed by Caer 9.72 (1.43); Ab followed by Caer 3.67 (0.38). ${ }^{\star} p<0.05$, antibody treated animals with acute pancreatitis compared with placebo group.

\section{Methods}

INDUCTION OF ACUTE PANCREATITIS

All experiments were performed under a current Home Office project licence. Caerulein was obtained from Research Plus (Bayonne, New Jersey, USA). Wistar rats (200-250 g) were randomly assigned to control or experimental groups ( $n=8$ for each group). Animals were given hourly intraperitoneal injections of saline (control) or saline containing a supramaximally stimulating dose of caerulein (50 $\mu \mathrm{g} / \mathrm{kg}$ ) for six hours. Anti-CINC antibody was produced as previously described ${ }^{13}$ and administered to rats at a dose of $8 \mathrm{mg} / \mathrm{kg}$ intraperitoneally either 30 minutes before (to determine prophylactic effects) or one hour after (to determine therapeutic effects) the first caerulein injection. This dose has been used in a number of previous studies in other models of inflammation in the rat to neutralise CINC
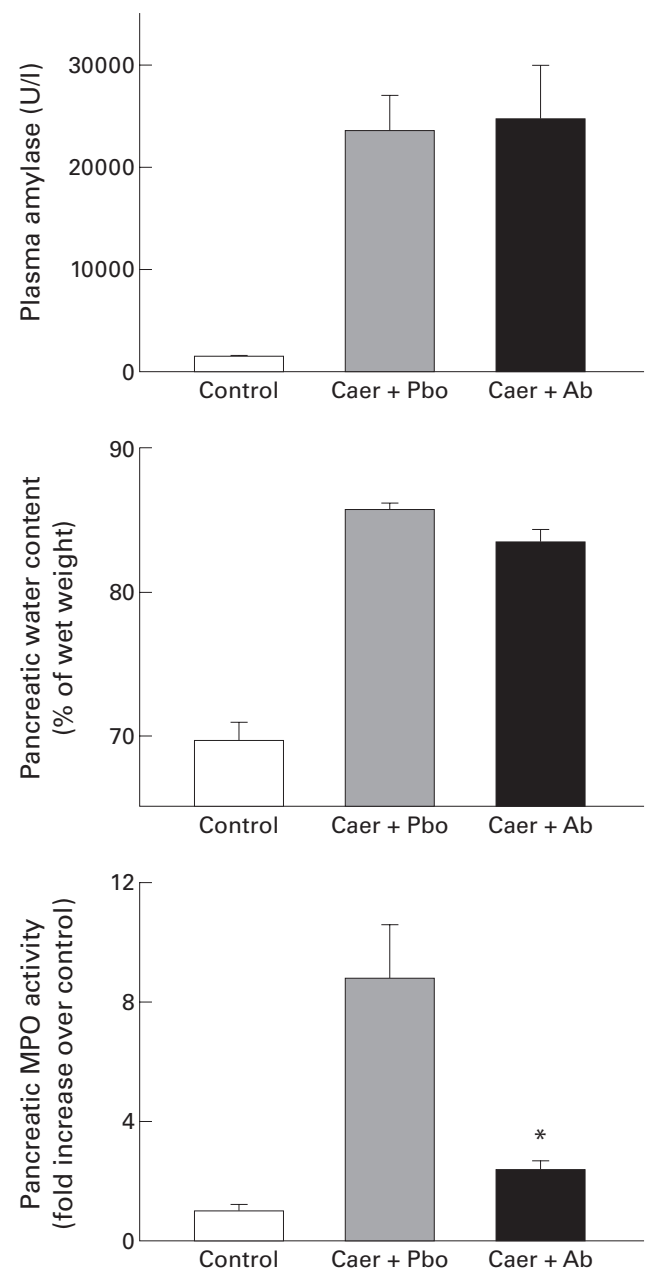

Figure 2 Effects of therapeutic treatment with anti-cytokine induced neutrophil chemoattractant antibody (anti-CINC antibody) on acute pancreatitis. The results shown are the mean (SEM) for eight animals in each group. The results are as follows: plasma amylase (U/l) - control 1593 (54); caerulein (Caer) followed by placebo (Pbo) 23860 (3377); Caer followed by anti-CINC antibody (Ab) 25046 (5337); pancreatic water content (\% of wet weight) — control 69.7 (1.2); Caer followed by Pbo 86.1 (0.5); Caer followed by Ab 83.8 (0.9); pancreatic myeloperoxidase (MPO) activity (fold increase over control) - control 1.0 (0.26); Caer followed by Pbo 8.86 (1.8); Caer followed by Ab 2.38 (0.3). ${ }^{\star} p<0.05$, antibody treated animals with acute pancreatitis compared with placebo group. 

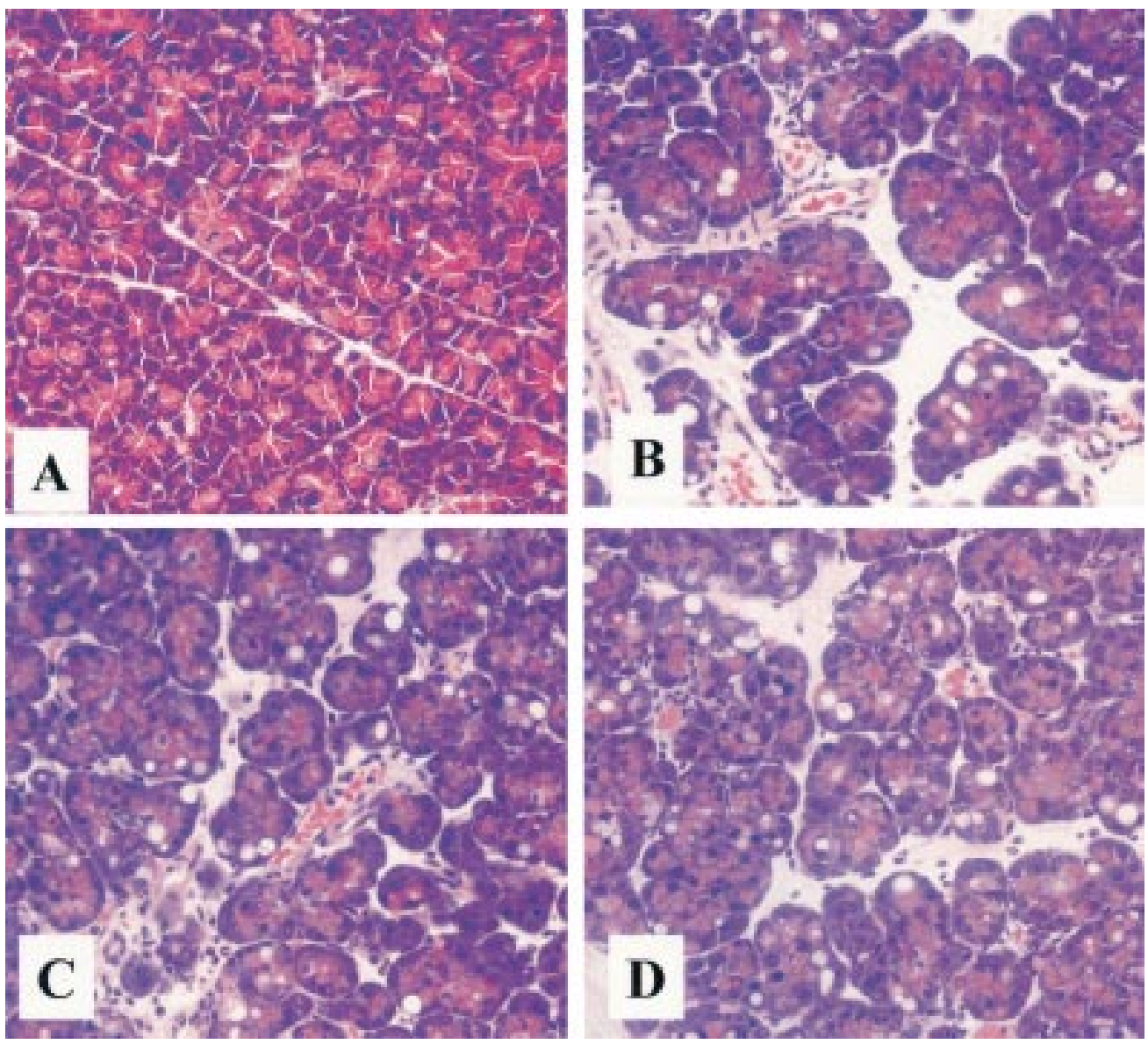

Figure 3 Morphological changes in rat pancreas on induction of acute pancreatitis with/without treatment with anti-cytokine induced neutrophil chemoattractant antibody (anti-CINC antibody). (A) Control: no pancreatitis. (B) Caerulein induced acute pancreatitis with placebo. (C) Caerulein induced acute pancreatitis with prophylactic treatment with anti-CINC antibody. (D) Caerulein induced acute pancreatitis with therapeutic treatment with anti-CINC antibody.

activity. ${ }^{14-16}$ One hour after the last caerulein injection, animals were sacrificed by an intraperitoneal injection of a lethal dose of pentabarbitone and samples rapidly prepared for storage.

Harvested heparinised blood was centrifuged (3000 $\mathrm{g}, 15$ minutes, $\left.4^{\circ} \mathrm{C}\right)$, plasma removed, and stored at $-70^{\circ} \mathrm{C}$. Random cross sections of the head, body, and tail of the pancreas and samples of the right lung were fixed in $4 \%$ neutral phosphate buffered formalin for 48 hours and then embedded in paraffin wax. A sample of pancreas was weighed and dried for 72 hours at $60^{\circ} \mathrm{C}$ and reweighed to determine pancreatic water content. ${ }^{17}$ Samples of pancreas and lung were removed, weighed, and stored at $-70^{\circ} \mathrm{C}$ for subsequent measurement of tissue myeloperoxidase (MPO) activity, as described below.

Table 1 Pancreatic injury (histological evidence) in caerulein induced pancreatitis on prophylactic/therapeutic treatment with anti-cytokine induced neutrophil chemoattractant antibody (anti-CINC antibody)

\begin{tabular}{|c|c|c|c|c|c|}
\hline & \multirow[b]{2}{*}{ Control } & \multicolumn{2}{|l|}{ Prophylactic } & \multicolumn{2}{|l|}{ Therapeutic } \\
\hline & & $\begin{array}{l}\text { Caerulein+ } \\
\text { placebo }\end{array}$ & $\begin{array}{l}\text { Caerulein }+ \\
\text { antibody }\end{array}$ & $\begin{array}{l}\text { Caerulein+ } \\
\text { placebo }\end{array}$ & $\begin{array}{l}\text { Caerulein }+ \\
\text { antibody }\end{array}$ \\
\hline Oedema & $<0.5$ & $1.9(0.2)^{\star}$ & $1.4(0.3)^{\star}$ & $1.7(0.3)^{\star}$ & $1.9(0.3)^{\star}$ \\
\hline Inflammation & $<0.5$ & $1.3(0.2)^{\star}$ & $1.6(0.3)^{\star}$ & $1.4(0.2)^{\star}$ & $1.1(0.1)^{\star}$ \\
\hline Necrosis & $<0.5$ & $<0.5$ & $<0.5$ & $<0.5$ & $<0.5$ \\
\hline
\end{tabular}

${ }^{\star} \mathrm{p}<0.05 v$ control, Mann Whitney U test.
AMYLASE ESTIMATION

Amylase activity was measured using a kinetic spectrophotometric assay. Plasma samples were incubated with the substrate, 4,6ethylidene $\quad\left(\mathrm{G}_{7}\right)$-p-nitrophenyl $\quad\left(\mathrm{G}_{1}\right)$-1-Dmaltoheptoside (Sigma, St Louis, Missouri, USA) for two minutes at $37^{\circ} \mathrm{C}$ and absorbance measured every minute for the subsequent two minutes at $405 \mathrm{~nm} .{ }^{17}{ }^{18}$ The change in absorbance was used to calculate amylase activity.

MYELOPEROXIDASE ESTIMATION

Neutrophil sequestration in pancreas and lung was quantitated by measuring tissue MPO activity. ${ }^{17}$ Tissue samples were thawed, homogenised in $20 \mathrm{mM}$ phosphate buffer ( $\mathrm{pH} 7.4$ ), centrifuged $\left(10000 \mathrm{~g}, 10\right.$ minutes, $\left.4^{\circ} \mathrm{C}\right)$, and the resulting pellet resuspended in $50 \mathrm{mM}$ phosphate buffer $(\mathrm{pH} 6.0$ ) containing $0.5 \%$ hexadecyltrimethylammonium bromide (Sigma). The suspension was subjected to four cycles of freezing and thawing and further disrupted by sonication (40 seconds). The sample was then centrifuged $\left(10000 \mathrm{~g}\right.$, five minutes, $\left.4^{\circ} \mathrm{C}\right)$ and the supernatant used for the MPO assay. The reaction mixture consisted of the supernatant, $1.6 \mathrm{mM}$ tetramethylbenzidine (Sigma), $80 \mathrm{mM}$ sodium phosphate buffer ( $\mathrm{pH} 5.4$ ), and $0.3 \mathrm{mM}$ hydrogen peroxide. This mixture was incubated at $37^{\circ} \mathrm{C}$ for 110 seconds, the reaction terminated 
with $0.18 \mathrm{M} \mathrm{H}_{2} \mathrm{SO}_{4}$, and absorbance measured at $450 \mathrm{~nm}$. This absorbance was corrected for the calculated dry weight of the tissue sample used and results expressed as activity per unit of dry weight (fold increase over control).

MEASUREMENT OF PULMONARY MICROVASCULAR PERMEABILITY

Two hours before sacrifice, each animal received an intravenous bolus injection containing fluorescein isothiocyanate (FITC)albumin ( $5 \mathrm{mg} / \mathrm{kg}$, Sigma). Immediately after sacrifice, the trachea was exposed, the right bronchus clamped, and the left lung lavaged three times with $3.3 \mathrm{ml}$ of saline. The lavage fluid was combined, and FITC fluorescence was measured in the lavage fluid and plasma (excitation $494 \mathrm{~nm}$; emission $520 \mathrm{~nm}$ ). The ratio of fluorescence emission in lavage fluid to plasma was calculated and used as a measure of pulmonary microvascular permeability.

MORPHOLOGICAL EXAMINATION

Paraffin embedded pancreas and lung samples were sectioned $(4 \mu \mathrm{m})$, stained with haematoxylin/eosin, and examined by light microscopy by an experienced observer who was unaware of the sample identity. Pancreas sections were scored for necrosis, oedema, and inflammation on a scale of $0-3,0$ being the least severe and 3 being the most severe for each parameter. Similarly, lung sections were
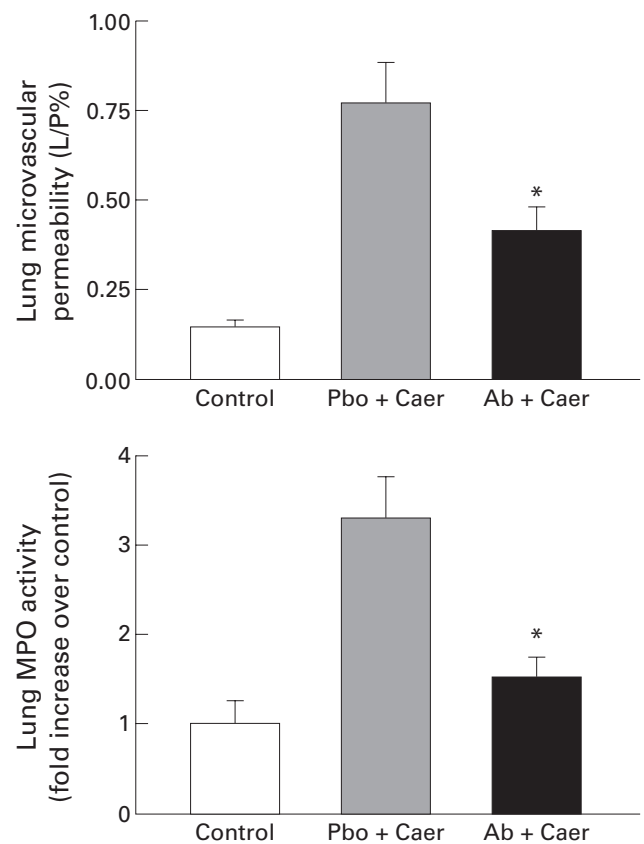

Figure 4 Effects of prophylactic treatment with anti-cytokine induced neutrophil chemoattractant antibody (anti-CINC antibody) on acute pancreatitis associated lung injury. The results shown are mean (SEM) for eight animals in each group. The results are as follows: pulmonary microvascular permeability (L/P\%) - control 0.15 (0.02); placebo (Pbo) followed by caerulein (Caer) 0.78 (0.11); anti-CINC antibody (Ab) followed by Caer 0.42 (0.04); lung myeloperoxidase (MPO) activity (fold increase over control) - control $1.0(0.26)$; Pbo followed by Caer 3.30 (0.46); Ab followed by Caer 1.53 (0.21).

${ }^{*} p<0.05$, antibody treated animals with acute pancreatitis compared with placebo group group. L/P, lavage to plasma FITC-albumin fluorescence ratio. scored for alveolar thickening (a measure of oedema) and inflammation, again on a scale of $0-3$.

\section{STATISTICS}

Results are given as mean (SEM). In all figures, vertical bars denote the SEM and the absence of such bars indicates that the SEM was too small to illustrate. Results were compared using an unpaired $t$ test unless stated otherwise; the level of significance was set at $5 \%$.

\section{Results}

EFFECT OF ANTI-CINC ANTIBODY TREATMENT ON PANCREATIC INJURY

Administration of supramaximal doses of caerulein to rats resulted in AP. This was confirmed by an increase in plasma amylase, pancreatic water content (a measure of pancreatic oedema), and pancreatic MPO (a measure of neutrophil infiltration in the pancreas) (fig 1). Prophylactic or therapeutic treatment with anti-CINC antibody did not have a significant effect on plasma levels of amylase or pancreatic water content (figs 1,2 ). MPO activity in the pancreas was, however, reduced in rats treated with the anti-CINC antibody. The morphological changes in the pancreas on induction of $\mathrm{AP}$ and the effect of prophylactic and therapeutic treatment with the anti-CINC antibody are shown in fig 3. The morphological changes in $\mathrm{AP}$, which in this model consisted principally of oedema, inflammation and some necrosis,
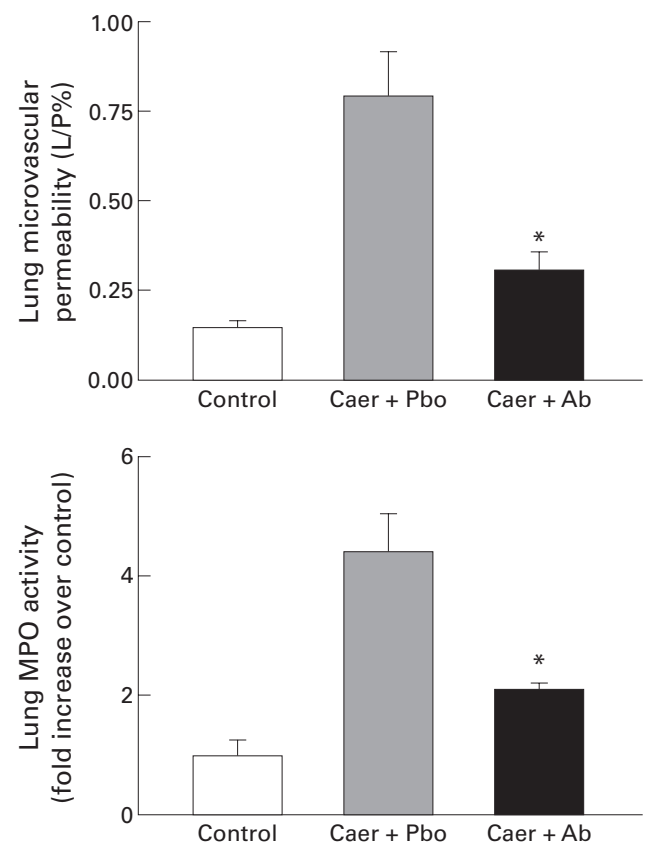

Figure 5 Effects of therapeutic treatment with anti-cytokine induced neutrophil chemoattractant antibody (anti-CINC antibody) on acute pancreatitis associated lung injury. The results shown are mean (SEM) for eight animals in each group. The results are as follows: pulmonary microvascular permeability $(L / P \%)$-control 0.15 (0.02); caerulein (Caer) followed by placebo (Pbo) 0.79 (0.12); Caer followed by anti-CINC antibody ( $A b)$ 0.31 (0.05); lung myeloperoxidase (MPO) activity (fold
increase over control) - control $1.0(0.26)$; Caer followed by Pbo 4.42 (0.64); Caer followed by Ab 2.13 (0.10).

${ }^{*} p<0.05$, antibody treated animals with acute pancreatitis compared with placebo group. L/P, lavage to plasma FITC-albumin fluorescence ratio. 


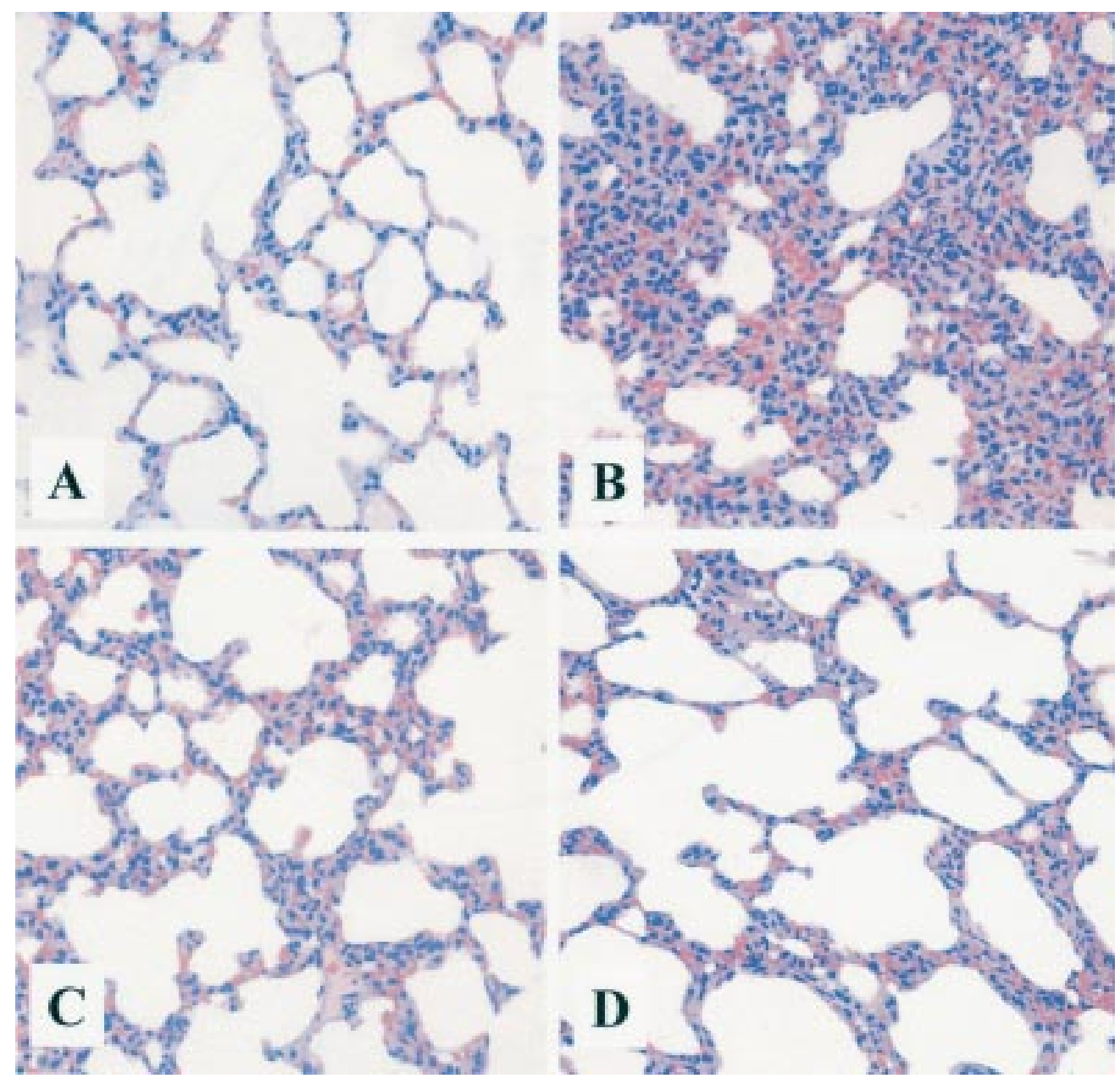

Figure 6 Morphological changes in rat lung on induction of acute pancreatitis with/without treatment with anti-cytokine induced neutrophil chemoattractant antibody (anti-CINC antibody). (A) Control: no pancreatitis. (B) Caerulein induced acute pancreatitis with placebo. (C) Caerulein induced acute pancreatitis with prophylactic treatment with anti-CINC antibody. (D) Caerulein induced acute pancreatitis with therapeutic treatment with anti-CINC antibody.

showed little difference between rats treated with the anti-CINC antibody and those treated with placebo (fig 3, table 1).

EFFECT OF ANTI-CINC ANTIBODY TREATMENT ON ACUTE PANCREATITIS ASSOCIATED LUNG INJURY Pancreatitis associated lung injury was confirmed by an increase in pulmonary microvascular permeability and an increase in lung MPO activity (figs 4,5 ). Prophylactic or therapeutic treatment with anti-CINC antibody significantly reduced pulmonary microvascular permeability and MPO levels in caerulein treated animals (figs 4,5 ). The morphological changes in the lung following induction of $\mathrm{AP}$ and the effect of prophylactic/therapeutic

Table 2 Lung injury (histological evidence) in caerulein induced pancreatitis on prophylactic/therapeutic treatment with anti-cytokine induced neutrophil chemoattractant antibody (anti-CINC antibody)

\begin{tabular}{|c|c|c|c|c|c|}
\hline & \multirow[b]{2}{*}{ Control } & \multicolumn{2}{|l|}{ Prophylactic } & \multicolumn{2}{|l|}{ Therapeutic } \\
\hline & & $\begin{array}{l}\text { Caerulein } \\
\text { +placebo }\end{array}$ & $\begin{array}{l}\text { Caerulein } \\
\text { +antibody }\end{array}$ & $\begin{array}{l}\text { Caerulein } \\
+ \text { placebo }\end{array}$ & $\begin{array}{l}\text { Caerulein } \\
\text { +antibody }\end{array}$ \\
\hline $\begin{array}{l}\text { Alveolar } \\
\text { thickening }\end{array}$ & $0.4(0.2)$ & $2.4(0.3)^{\star}$ & $0.8(0.3) \dagger$ & $2.3(0.3)^{\star}$ & $1.0(0.4) \dagger$ \\
\hline Inflammation & $0.4(0.2)$ & $2.6(0.2)^{\star}$ & $0.9(0.3) \dagger$ & $2.1(0.3)^{\star}$ & $1.0(0.4) \dagger$ \\
\hline
\end{tabular}

${ }^{\star} \mathrm{p}<0.05 v$ control

$t \mathrm{p}<0.05 v$ respective placebo, Mann-Whitney U test. treatment with the anti-CINC antibody are shown in fig 6. These consist principally of alveolar thickening and infiltration by inflammatory cells, the vast majority of which are neutrophils. After either prophylactic or therapeutic treatment with the anti-CINC antibody, alveolar thickening and inflammation, as determined by the histological scoring of lung sections, was reduced (fig 6 , table 2 ).

\section{Discussion}

The first sign of MODS in severe AP is often impaired lung function due to ARDS. As a consequence of overactive SIRS, leucocytes and in particular neutrophils become activated within the general circulation and attach to the pulmonary vascular endothelium. As the condition develops, leucocytes migrate into the pulmonary interstitium and increased endothelial permeability leads to tissue oedema. ${ }^{3}$ Leucocyte derived products are thought to contribute to pulmonary damage. Leucocyte activation and migration into tissue is a tightly regulated process. Although a number of proinflammatory cytokines such as IL- $1,{ }^{19} 20$ tumour necrosis factor $\alpha,{ }^{2122}$ and platelet activating factor ${ }^{2324}$ which have a broad profile of action are implicated, other more specific 
mediators such as chemokines may play a more central role.

Neutrophils also play an important role in local pancreatic damage in AP and more so in the translation of local pancreatic damage to a systemic inflammatory response. Neutrophil depletion partially reduces pancreatic damage in some models of AP but affords almost complete protection against $\mathrm{AP}$ associated lung injury. ${ }^{25-27}$ In an analogous manner, antibodies directed against ICAM-1, which interfere with neutrophil migration, reduce AP associated lung injury. ${ }^{28}$ Similarly, there is reduced AP associated lung injury following genetic deletion of ICAM-1. ${ }^{29}$

Chemokines are thought to influence leucocyte migration into tissues in two main ways. Firstly, binding of chemokine ligand to a leucocyte receptor leads to activation of cell surface integrins and allows strong adhesion to endothelium. Secondly, chemokines promote migration of adherent leucocytes across endothelium and through the extracellular matrix. In addition to leucocyte recruitment, chemokines may be important regulators of leucocyte activation in situ. The profile of chemokines expressed at a site of injury is likely to be one of the major factors that determines the nature of the subsequent leucocyte infiltrate. ${ }^{40-34}$

CINC, the rat homologue of human GRO- $\alpha$, is a $\mathrm{C}-\mathrm{x}-\mathrm{C}$ chemokine and a specific neutrophil chemoattractant and activator in vitro. ${ }^{103536}$ CINC has also been shown to induce neutrophil recruitment in vivo and specific antagonists reduce the inflammatory response in a number of different models of injury. ${ }^{35-38}$ It is therefore reasonable to suggest that neutralising the action of CINC would block neutrophil recruitment and activation in AP.

In this study, we have examined the effect of a neutralising anti-CINC antibody on pancreatic and lung damage using a model of AP induced by the pancreatic secretagogue caerulein. The increase in lung MPO levels and microvascular permeability shows evidence of AP associated lung injury. Treatment with the anti-CINC antibody resulted in significant protection against lung damage, as measured by pulmonary microvascular permeability. Histological examination of the lungs and lung MPO levels confirm reduced neutrophil infiltration and suggest that the antibody is interfering directly with leucocyte migration. Evidently, CINC plays an important role in neutrophil recruitment to the lungs although the exact molecular mechanism by which CINC acts as a mediator of AP associated lung injury remains to be investigated.

In patients with $\mathrm{AP}$ it is likely that a number of $\mathrm{C}-\mathrm{x}-\mathrm{C}$ chemokines are involved in neutrophil recruitment and activation. For example, plasma levels of IL-8, ${ }^{56}$ ENA-78, and GRO- $\alpha$ (Shokuhi S, Bhatia M, Slavin J, et al, unpublished) are elevated in patients with AP and correlate with disease severity. At the present time the range of $\mathrm{C}-\mathrm{x}-\mathrm{C}$ chemokines characterised in the rat is not as large as in humans. Although present evidence suggests that $\mathrm{CINC}$ is a major $\mathrm{C}-\mathrm{x}-\mathrm{C}$ chemokine in the rat, ${ }^{9-11}$ other $\mathrm{C}-\mathrm{x}-\mathrm{C}$ chemokines, such as CINC-2, CINC-3, and ENA-78 may conceivably play a role in $\mathrm{AP}$ and the associated systemic inflammatory response. For example, ENA-78 has previously been implicated in ischaemia/reperfusion induced liver injury in the rat, a condition similar to pancreatic injury in $\mathrm{AP}^{39} \mathrm{~A}$ possible involvement of other $\mathrm{C}-\mathrm{x}-\mathrm{C}$ chemokines may, in part, explain the partial rather than complete protection against lung injury following treatment with anti-CINC antibody.

Treatment with anti-CINC antibody did not appear to affect pancreatic damage in AP as determined by an increase in plasma amylase and pancreatic oedema. This is in agreement with previous studies suggesting that neutrophil mediated damage is not a major factor affecting the pancreas in caerulein induced $\mathrm{AP}^{8}{ }^{86-29}$

It is important to acknowledge the distinction between prophylactic and therapeutic use of an agent in AP. Obviously the latter is of relevance in a clinical setting where therapeutic intervention is proposed. Lung injury becomes manifest some hours after the onset of an attack of AP and it is often maximal between 48 and 96 hours. As pain is an early feature, it has been proposed that there is a therapeutic window during which anti-inflammatory therapy might be effective in $\mathrm{AP}^{3}$ It is encouraging that administration of anti-CINC antibody after induction of AP was as effective in reducing lung damage as prophylactic administration, and suggests that strategies that seek to interfere with chemokine function might be of clinical use.

1 McKay CJ, Evans S, Sinclair M, et al. High early mortality rate from acute pancreatitis in Scotland, 1984-1995. Br F Surg 1999;86:1302-5.

2 Neoptolemos JP, Raraty M, Finch $\mathrm{M}$, et al. Acute pancreatitis: the substantial human and financial costs. Gut 1998;42:886-91.

3 Bhatia, M, Brady, M, Shokuhi, S, et al. Inflammatory mediators in acute pancreatitis. F Pathol 2000;190:117-25.

4 Adams DH, Lloyd AR. Chemokines: leucocyte recruitment adams DH, Lloyd AR. Chemokines: leucocyte recru

5 Gross V, Andreesen R, Leser HG, et al. Interleukin-8 and Gross V, Andreesen R, Leser HG, et al. Interleukin-8 and
neutrophil activation in acute pancreatitis. Eur $\mathcal{f}$ Clin Invest 1992;22:200-3

6 Berney T, Gasche Y, Robert J, et al. Serum profiles of interleukin-6, interleukin-8, and interleukin-10 in patients with severe and mild acute pancreatitis. Pancreas 1999;18: 371-7.

7 Osman MO, Kristensen JU, Jacobsen NO, et al. A monoclonal anti-interleukin 8 antibody (WS-4) inhibits cytokine response and acute lung injury in experimental severe acute necrotising pancreatitis in rabbits. Gut 1998;43:232-9.

8 Gerard C, Frossard JL, Bhatia M, et al. Targeted disruption of the beta-chemokine receptor CCR1 protects against pancreatitis-associated lung injury. F Clin Invest 1997;100: pancreatitis 2022 .

9 Haskill S, Peace A, Morris J, et al. Identification of three related human GRO genes encoding cytokine functions. related human GRO genes encoding cyt
Proc Natl Acad Sci USA 1990;87:7732-6.

10 Watanabe K, Konishi K, Fujioka M, et al. The neutrophil chemoattractant produced by the rat kidney epithelioid cell line NRK-52E is a protein related to the $\mathrm{KC} /$ gro protein. $\mathcal{F}$ Biol Chem 1989;264:19559-63.

11 Nakagawa H, Komorita N, Shibata F, et al. Identification of cytokine-induced neutrophil chemoattractants (CINC), rat GRO/CINC-2 alpha and CINC-2 beta, produced by granulation tissue in culture: purification, complete amino acid sequences and characterization. Biochem $\mathcal{f}$ 1994;301: 545-50.

12 Brady M, Bhatia M, Zagorski J, et al. CINC and MCP-1 expression in early acute pancreatitis. Pancreas 1999;19: 416.

13 Wittwer AJ, Carr LS, Zagorski J, et al. High-level expression of cytokine-induced neutrophil chemoattractant (CINC) by a metastatic rat cell line: purification and production of blocking antibodies. $\mathcal{F}$ Cell Physiol 1993;156:421-7. 
14 Fan J, Marshall JC, Jimenez M, et al. Hemorrhagic shock primes for increased expression of cytokine-induced neutrophil chemoattractant in the lung: role in pulmonary inflammation following lipopolysaccharide. $\mathcal{f}$ Immuno 1998;161:440-7.

15 Zagorski J, Wahl SM. Inhibition of acute peritoneal inflammation in rats by a cytokine-induced neutrophil chemoattractant receptor antagonist. F Immunol 1997;159:1059-62.

16 Yamasaki Y, Matsuo Y, Zagorski J, et al. New therapeutic possibility of blocking cytokine-induced neutrophil chemoattractant on transient ischemic brain damage in rats. Brain Res 1997;759:103-11.

17 Bhatia M, Saluja AK, Hofbauer B, et al. Role of substance P and the neurokinin 1 receptor in acute pancreatitis and pancreatitis-associated lung injury. Proc Natl Acad Sci USA 1998;95:4760-5.

18 Pierre KJ, Tung KK, Nadj H. A new enzymatic kinetic method for the determination of serum and urine amylase. Clin Chem 1976;22:1219.

19 Fink GW, Norman JG. Specific changes in the pancreatic expression of the interleukin-1 family of genes during

20 Norman J, Franz M, Messina J, et al. Interleukin-1 receptor antagonist decreases severity of experimental acute pancreatitis. Surgery 1995;117:648-55.

21 Gukovskaya AS, Gukovsky I, Zaninovic V, et al. Pancreatic acinar cells produce, release, and respond to tumor necrosis factor-alpha. Role in regulating cell death and pancreatitis. F Clin Invest 1997;100:1853-62.

22 Norman JG, Fink GW, Franz MG. Acute pancreatitis induces intrapancreatic tumor necrosis factor gene expression. Arch Surg 1995;130:966-70.

23 Sandoval D, Gukovskaya A, Reavey P, et al. The role of neutrophils and platelet-activating factor in mediating experi-
mental pancreatitis. Gastroenterology 1996;111:1081-91.

24 Hofbauer B, Bhatia M, Frossard JL, et al. Effect of recombinant platelet-activating factor acetylhydrolase on two models of experimental acute pancreatitis. Gastroenterology 1998;115:1238-47.

25 Fujimoto K, Hosotani R, Doi R, et al. Role of neutrophils in cerulein-induced pancreatitis in rats: possible involvement cerulein-induced pancreatitis in rats: possi
of apoptosis. Digestion 1997;58:421-30.

26 Bhatia M, Hofbauer B, Lee HS, et al. The effects of neutrophil depletion on a completely noninvasive model of acute pancreatitis-associated lung injury. Int f Pancreatol 1998; 24:77-83.
27 Inoue S, Nakao A, Kishimoto W, et al. Anti-neutrophil antibody attenuates the severity of acute lung injury in rats with experimental acute pancreatitis. Arch Surg 1995:130:93-8.

28 Werner J, Z'graggen K, Fernandez-del Castillo C, et al. Specific therapy for local and systemic complications of acute pancreatitis with monoclonal antibodies against ICAM-1. Ann Surg 1999;229:834-40.

29 Frossard JL, Saluja A, Bhatia M, et al. The role of intercellular adhesion molecule 1 and neutrophils in acute pancreatitis and pancreatitis-associated lung injury. Gastroenterology 1999;116:694-701.

30 Campbell JJ, Hedrick J, Zlotnik A, et al. Chemokines and the arrest of lymphocytes rolling under flow conditions. Science 1998;279:381-4.

31 Baggiolini M. Chemokines and leukocyte traffic. Nature 1998;392:565-8.

32 Butcher EC. Leukocyte-endothelial cell recognition: three (or more) steps to specificity and diversity. Cell 1991;67: 1033-6.

33 Adams DH, Shaw S. Leucocyte-endothelial interactions and regulation of leucocyte migration. Lancet 1994;343: 831-6.

34 Butcher EC, Picker LJ. Lymphocyte homing and homeostasis. Science 1996;272:60-6.

35 Hirasawa $\mathrm{N}$, Watanabe $\mathrm{M}$, Mue $\mathrm{S}$, et al. Induction of neutrophil infiltration by rat chemotactic cytokine (CINC) and its inhibition by dexamethasone in rats. Inflammation 1992;16:187-96.

36 Yamasawa H, Ishii Y, Kitamura S. Cytokine-induced neutrophil chemoattractant in a rat model of lipopolysaccharide-induced acute lung injury. Inflammation 1999;23:263-74.

37 Suzuki H, Suematsu M, Miura S, et al. Rat CINC/gro: a novel mediator for locomotive and secretagogue activation of neutrophils in vivo. F Leukoc Biol 1994;55:652-7.

38 Davenpeck KL, Zagorski J, Schleimer RP, et al. Lipopolysaccharide-induced leukocyte rolling and adhesion in the rat mesenteric microcirculation: regulation by glucocorticoids and role of cytokines. F Immunol 1998;161: 6861-70.

39 Colletti LM, Kunkel SL, Walz A, et al. The role of cytokine networks in the local liver injury following hepatic ischemia/reperfusion in the rat. Hepatology 1996;23: 506-14

\section{8th United European Gastroenterology Week}

The UEGW abstract book (Gut 2000;47(suppl III)) has again been produced as a CD-ROM and can be found attached to the inside back cover of this issue. 